Marquette University

e-Publications@Marquette

Biological Sciences Faculty Research and

Publications

Biological Sciences, Department of

$4-1-1988$

\title{
Transformation of Tetrahymena thermophila with Hypermethylated rRNA Genes
}

Kathleen M. Karrer

Marquette University, kathleen.karrer@marquette.edu

Meng-Chao Yao

Fred Hutchinson Cancer Research Center

Published version. Molecular and Cellular Biology, Vol. 8, No. 4 (April 1988): 1664-1669. Permalink. (C) 1988 American Society for Microbiology. Used with permission.

Kathleen Karrer was affiliated with Brandeis University at the time of publication. 


\title{
Transformation of Tetrahymena thermophila with Hypermethylated rRNA Genes
}

\author{
KATHLEEN M. KARRER ${ }^{1 *}$ AND MENG-CHAO YAO ${ }^{2}$ \\ Department of Biology, Brandeis University, Waltham, Massachusetts 02254, ${ }^{1}$ and Division of Basic Sciences, \\ Fred Hutchinson Cancer Research Center, Seattle, Washington $98104^{2}$
}

Received 28 September 1987/Accepted 21 January 1988

\begin{abstract}
The extrachromosomal rRNA genes (rDNA) of Tetrahymena thermophila contain $0.4 \% N^{6}$-methyladenine. C3 strain rDNA was isolated, hypermethylated in vitro, and microinjected into B strain host cells. Clonal cell lines were established, and transformants were selected on the basis of resistance to paromomycin, conferred by the injected rDNA. The effects of methylation by three enzymes which methylate the sequence $5^{\prime}-N^{\prime} \mathbf{A T}^{-3^{\prime}}$, the dam, EcoRI, and ClaI methylases, were tested. Hypermethylation of the injected rDNA had no effect on transformation efficiency relative to mock-methylated controls. The injected C3 strain rDNA efficiently replaced host rDNA as the major constituent of the population of rDNA molecules. Hypermethylation of the injected DNA was not maintained through 20 to 25 cell generations.
\end{abstract}

One model for maintenance of methylation patterns in eucaryotes holds that a fully methylated site becomes hemimethylated during DNA replication and that the maintenance methylase acts preferentially at hemimethylated sites to methylate the daughter strand $(3,14,25)$. Although in vitro studies indicate that hemimethylated DNA is a preferred substrate for maintenance methylases $(12,26,29,30)$, it is not clear how important this is in maintenance of patterns of methylation.

This question has been addressed in vivo by introducing methylated heterologous DNA into mammalian tissue culture cells and asking whether the methylation is maintained through several rounds of DNA replication. In general, the results demonstrate clonal inheritance of methylation at some level which is variable in different clonal cell lines and at different sequences within a single transformant and depends on the transfected cell type, as well as on the mode and extent of in vitro hypermethylation $(15,24,27,31,32)$.

In the macronuclear DNA of the ciliated protozoan Tetrahymena thermophila, $0.8 \%$ of the adenine residues are modified to $N^{6}$-methyladenine (10). Sites have been identified which are methylated in all 45 copies of the DNA in the polygenomic macronucleus $(13,18)$. No uniformly methylated sites have been found in the extrachromosomal rDNA, but some sites are methylated in a small percentage of the molecules (4).

Recently, methods have been developed for transformation of Tetrahymena macronuclei by microinjection of rDNA (28). This provides a particularly advantageous system for analysis of clonal inheritance of methylation because it is possible to examine methylation of a homologous gene. Furthermore, since the rDNA of $T$. thermophila is extrachromosomal, the methylation pattern is not influenced by the state of the surrounding chromatin, as it may be in systems in which the transforming DNA is integrated in the genome.

We isolated native rDNA and hypermethylated it in vitro with three different bacterial enzymes. Hypermethylation had no effect on the transformation frequency obtained when the DNA was injected into vegetative host cells. Within the 20 to 25 cell fissions required to obtain DNA from clonal cell

\footnotetext{
* Corresponding author.
}

lines, the pattern of methylation reverted to that of the native rDNA. Hypermethylation of adenine was not maintained faithfully, even at sites methylated at a low level in vivo. Thus, sites of rDNA methylation must be primarily determined by factors other than preferance of the maintenance methylase for a hemimethylated substrate.

\section{MATERIALS AND METHODS}

Strains and cell culture. The B strain cell line SB255 (exolexo, $\mathrm{pmr}^{+} / \mathrm{pmr}^{+}$[paromomycin sensitive, mucocystless, mating type IV]) (20) was the host strain for microinjection. rDNA was isolated from strain SL061a (pmr/pmr [paromomycin resistant]). Strain SL061 was constructed as described previously for strain SL062 (28). It was then mated to strain $A^{*}$, and a clonal cell line, SL061a, was isolated from the drug-resistant progeny.

Clonal cell lines were established from the injected cells by isolation of single cells into individual drops of axenic medium (11) as described by Orias and Bruns (19). Clonal cell lines were tested for resistance to paromomycin by replica plating into medium containing $100 \mu \mathrm{g}$ of paromomycin per $\mathrm{ml}$. Clones that contained large numbers of vigorous, dividing cells after 2 days in paromomycin were scored as drug resistant. To obtain cellular DNA for Southern analysis, all of the cells in a clone were transferred to $10 \mathrm{ml}$ of medium with $100 \mu \mathrm{g}$ of paromomycin per $\mathrm{ml}$ and grown in shaking culture at $28^{\circ} \mathrm{C}$ to a density of $0.5 \times 10^{6}$ to $1.0 \times 10^{6}$ cells per ml.

DNA isolation. Native macronuclear rDNA was isolated from strain SL061a by the hot phenol-cresol method of Din and Engberg (9). Whole-cell DNA was prepared from clonal cell lines by the method of Austerberry and Yao (2). In some cases, an additional precipitation was done by adding 0.4 volume of $5 \mathrm{M} \mathrm{NH}_{4} \mathrm{OAc}$ and 2 volumes of isopropanol at room temperature for $10 \mathrm{~min}$ to facilitate restriction enzyme digestion.

In vitro methylation. rDNA was methylated in vitro with ClaI, dam, or EcoRI methylase (New England BioLabs, Inc.) as recommended by the supplier. Control samples were mock methylated by incubation under the same conditions but in the absence of the enzyme.

Microinjection. Cells were transformed by microinjection as described by Tondravi and Yao (28). 
Southern analysis. DNA was digested with restriction enzymes supplied by New England BioLabs in a universal restriction buffer of $66 \mathrm{mM}$ potassium acetate-10 $\mathrm{mM}$ magnesium acetate- $33 \mathrm{mM}$ Tris acetate $(\mathrm{pH} 7.9)-5 \mathrm{mM}$ dithiothreitol. The fragments were separated on agarose gels and transferred to nitrocellulose membranes as described by Allitto and Karrer (1). Filters were probed with nick-translated pTt947, a clone of the micronuclear rDNA, and 5.4 kilobases $(\mathrm{kb})$ of flanking sequences in p1C19. Hybridizations were done at $65^{\circ} \mathrm{C}$ overnight in $4 \times$ SSPE $(1 \times$ SSPE is $0.18 \mathrm{M} \mathrm{NaCl}, 10 \mathrm{mM} \mathrm{NaH} \mathrm{PO}_{4}, 1 \mathrm{mM}$ disodium EDTA [pH 7.4]-100 mM Tris (pH 7.4)-0.5\% sodium dodecyl sulfate-2× Denhardt solution. Filters were washed in $2 \times$ SSPE at room temperature for $2 \mathrm{~h}$, except for the filter in Fig. $4 \mathrm{c}$, which was washed in $0.5 \times \mathrm{SSPE}$ at $65^{\circ} \mathrm{C}$.

DNA sequence analysis. The complete sequence of $B$ strain rDNA was compiled from data acquired in a number of laboratories and generously supplied by $\mathrm{H}$. Nielsen and $\mathrm{J}$. Engberg. Restriction maps were drawn on the basis of the sequence data by using a MacIntosh computer and the DNA Inspector program (Textco).

Densitometry. Autoradiograms were scanned with a densitometer (CE-C Apparatus Corp.), and the intensities of bands were determined with a Hewlett-Packard model $3390 \mathrm{~A}$ integrator.

\section{RESULTS}

Hypermethylation of rDNA in vitro. Extrachromosomal rDNA was isolated from the C3-derived strain SL061a. The rDNA was injected into vegetative cells of the mucocystless B strain line SB255 (20) at a concentration of $100 \mathrm{ng} / \mu \mathrm{l}$ as described by Tondravi and Yao (28). Under these circumstances, the injected rDNA, which is thought to have a replication advantage over the B strain rDNA (16), was known to become the major constituent of the population of rDNA molecules in transformed cells and to confer paromomycin resistance (28). Clonal cell lines were established and assayed for transformation by replica plating into medium containing $100 \mu \mathrm{g}$ of paromomycin per ml. The transformation frequencies in two separate experiments were $30 \%(18 / 61)$ and $55 \%(52 / 94)$ of the injected cells.

Three methylases, the dam methylase, EcoRI methylase, and ClaI methylase, were chosen for the hypermethylation experiments because they have $5^{\prime}-\mathrm{NAT}-3^{\prime}$, the sequence methylated by the Tetrahymena enzyme (5), as part of their recognition sequences. The sequence recognized by the dam methylase ( $5^{\prime}$ GATC $3^{\prime}$ ) occurs 29 times on each half of the palindromic rDNA. A single EcoRI site (5' GAATTC $3^{\prime}$ ) and three ClaI sites (5' ATCGAT 3') are on each half molecule.

Three samples of rDNA were hypermethylated in vitro with the dam methylase, the EcoRI methylase, and the ClaI methylase as described in Materials and Methods. Samples of hypermethylated and control, mock-methylated rDNA were treated with restriction enzymes to assess the efficiency of methylation. Figure la shows a Southern blot of the DNAs hybridized with nick-translated pTt947, a clone of the micronuclear rDNA (M.-C. Yao and C.-H. Yao, unpublished data). Lanes $\mathrm{N}$ contained native rDNA. The rDNA was digested with $C l a I$ and EcoRI, respectively, to fragments of the sizes expected from the computer analysis of the rDNA sequence. The absence of undigested rDNA or detectable levels of fragments of the sizes expected for partial digests suggested that the rDNA was not detectably methylated at these sites in vivo.

The in vitro methylation was very efficient. Lanes $H$ contained rDNA hypermethylated with the ClaI and EcoRI methylases and subsequently treated with the corresponding restriction enzymes. To the level of sensitivity of the Southern blot analysis, the DNAs were completely resistant to digestion with the restriction enzymes. No fragments of the sizes expected for ClaI or EcoRI digestion were detectable, even after very long exposures. Densitometric analysis of longer exposures revealed that $<0.2 \%$ of the $E c o$ RI sites and $<1.0 \%$ of the ClaI sites remained susceptible to enzymatic digestion after treatment with the methylase. Since the mock-methylated samples (Fig. 1, lanes $\mathbf{M}$ ) were digested to the same extent as the control, resistance to the restriction enzymes was attributed to methylation at the recognition sites.

Because of the large number of fragments generated by enzymes that cut Tetrahymena rDNA at the sequence $5^{\prime}$ GATC 3', it is more difficult to assess the efficiency of methylation with the dam methylase. Figure $1 \mathrm{~b}$ shows a Southern blot of a gel containing rDNA digested with $\mathrm{MboI}$, which does not cut if the adenine in either strand is methylated. A $2 \%$ agarose gel was run to retain the small fragments; thus, the 3.8-kb central fragment in lanes $\mathrm{N}$ and $\mathrm{M}$ comigrated with the intact native DNA. Three minor bands were seen in the lane containing rDNA which was hypermethylated and then digested (lane $\mathrm{H}$ ), but comparison of that sample with the digested DNA in the adjacent lanes indicated that the rDNA was heavily hypermethylated.

Lack of effect of hypermethylation on transformation frequency. Hypermethylated rDNA and mock-methylated control rDNA, at approximately $15 \mathrm{ng} / \mu \mathrm{l}$, were microinjected into the macronuclei of vegetative B strain SB255 cells as described by Tondravi and Yao (28). Clonal cell lines were established from the injected cells and grown for 3 days. The cells were then replica plated to fresh medium and to medium containing $100 \mu \mathrm{g}$ of paromomycin per ml. Cells containing transcriptionally active rDNA of the injected type are resistant to paromomycin because of a point mutation in the 17S rRNA gene. After 2 days in paromomycin, the numbers of resistant and sensitive clones were counted. There was no significant difference in the efficiency of

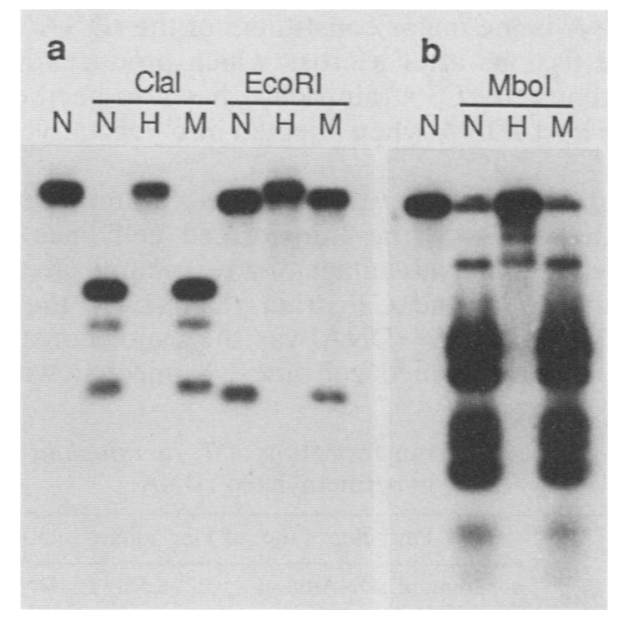

FIG. 1. rDNA for microinjection was hypermethylated with ClaI, EcoRI, or dam methylase. Resistance to digestion with ClaI, $E c o R I$, and $M b o I$ restriction enzymes, respectively, demonstrated efficient in vitro methylation. Lanes: $N$, native rDNA; $H$, hypermethylated rDNA; M, mock-methylated rDNA. Southern blots of the rDNA were hybridized with nick-translated pTt947, a clone of the micronuclear form of rDNA. Panels: a, $0.7 \%$ agarose gel in TBE, $200 \mathrm{~V}-\mathrm{h}$; b, $2 \%$ agarose gel in TBE $(89 \mathrm{mM}$ Tris base, $89 \mathrm{mM}$ boric acid, 2 mM disodium EDTA; pH 8.0), 250 V-h. 
transformation between hypermethylated rDNA and mockmethylated controls (Table 1).

Host cells have about 9,000 copies of B strain rDNA. Assuming that about $0.1 \mathrm{pl}$ was injected into each cell, a concentration of $15 \mathrm{ng} / \mu \mathrm{l}$ would represent approximately 45 molecules of C3 strain rDNA injected into each cell. During the 3 days of clonal cell growth in the absence of drug, the proportion of injected rDNA must increase to a level sufficient to confer drug resistance. A few of the clones were ambiguous as to their resistance. It was likely that the cells in some clones were only marginally resistant because they still had a low proportion of C3 type rDNA. After 6 days in culture without paromomycin, clones whose drug sensitivity had been ambiguous at 3 days showed clear resistance.

A second set of injections was done at reduced concentrations of injected rDNA to decrease the probability that transformation with hypermethylated DNA could be attributed to a few molecules in the population which might have escaped the methylation treatment. Tondravi and Yao (28) observed that the frequency of transformation dropped off abruptly between 4 and $0.8 \mathrm{ng}$ of rDNA per $\mu$ l of injection buffer. We therefore injected DNA at a concentration of 1.5 $\mathrm{ng} / \mu \mathrm{l}$ or about 4 or 5 injected molecules per cell. The results are shown in Table 1 . There was a small but consistent reduction in the transformation frequency with the more dilute samples. There was also a generally greater increase in transformants in clones tested at 6 days versus 3 days of growth. It might be expected in cases in which very few molecules are injected that more time is required before the injected rDNA becomes sufficiently established in the cells to confer drug resistance. There was no significant difference in the frequency of transformation between mock-methylated and hypermethylated DNAs. These experiments indicated that hypermethylated DNA is both replicated and transcribed in host cells.

C3 strain rDNA in place of host $B$ strain rDNA as the major proportion of the rDNA molecules in transformed cells. Injected C3 strain rDNA is thought to have a replication advantage over the host B strain rDNA because of sequence differences in the region of the origin of replication. Thus, $\mathrm{C} 3$ strain rDNA is the major constituent of the rDNA within 20 vegetative fissions after a cross which produces heterozygous progeny (16). C3 strain rDNA has also been observed to replace host rDNA when injected into vegetative $B$ strain cells (28).

Southern blot analysis was done to ascertain what proportion of the rDNA in the transformed cell lines was the injected type, taking advantage of a restriction site polymorphism between $B$ and $C 3$ strain rDNAs for the enzyme BamHI (28). C3 strain rDNA was the major constituent of rDNA in 36 transformed cell lines: 8 injected with ClaI-,

TABLE 1. Transformation of T. thermophila with hypermethylated rDNA

\begin{tabular}{|c|c|c|c|c|}
\hline \multirow{3}{*}{ Hypermethylation } & \multicolumn{4}{|c|}{$\% \mathrm{Pmr}^{r}$ clones (no. of $\mathrm{Pmr}^{r}$ clones/total) with: } \\
\hline & \multicolumn{2}{|c|}{$\begin{array}{l}15 \mathrm{ng} \text { of } \mathrm{rDNA} / \mathrm{ml} \text { of } \\
\text { injection buffer }\end{array}$} & \multicolumn{2}{|c|}{$\begin{array}{l}1.5 \mathrm{ng} \text { of } \mathrm{rDNA} / \mathrm{ml} \text { of } \\
\text { injection buffer }\end{array}$} \\
\hline & 3 days & 6 days & 3 days & 6 days \\
\hline $\begin{array}{l}\text { Mock } \\
\text { dam } \\
\text { ClaI }\end{array}$ & $\begin{array}{l}39(31 / 79) \\
34(35 / 103) \\
46(37 / 89)\end{array}$ & $\begin{array}{l}44(35 / 79) \\
37(38 / 103) \\
49(44 / 90)\end{array}$ & $\begin{array}{l}21(26 / 126) \\
21(25 / 120) \\
44(62 / 140)\end{array}$ & $\begin{array}{l}29(38 / 129) \\
39(47 / 122) \\
66(92 / 140)\end{array}$ \\
\hline $\begin{array}{l}\text { Mock } \\
\text { EcoRI }\end{array}$ & $\begin{array}{l}47(43 / 92) \\
42(69 / 164)\end{array}$ & $\begin{array}{l}53(49 / 92) \\
51(83 / 163)\end{array}$ & $\begin{array}{l}37(47 / 128) \\
15(20 / 130)\end{array}$ & $\begin{array}{l}39(50 / 128) \\
26(36 / 136)\end{array}$ \\
\hline
\end{tabular}

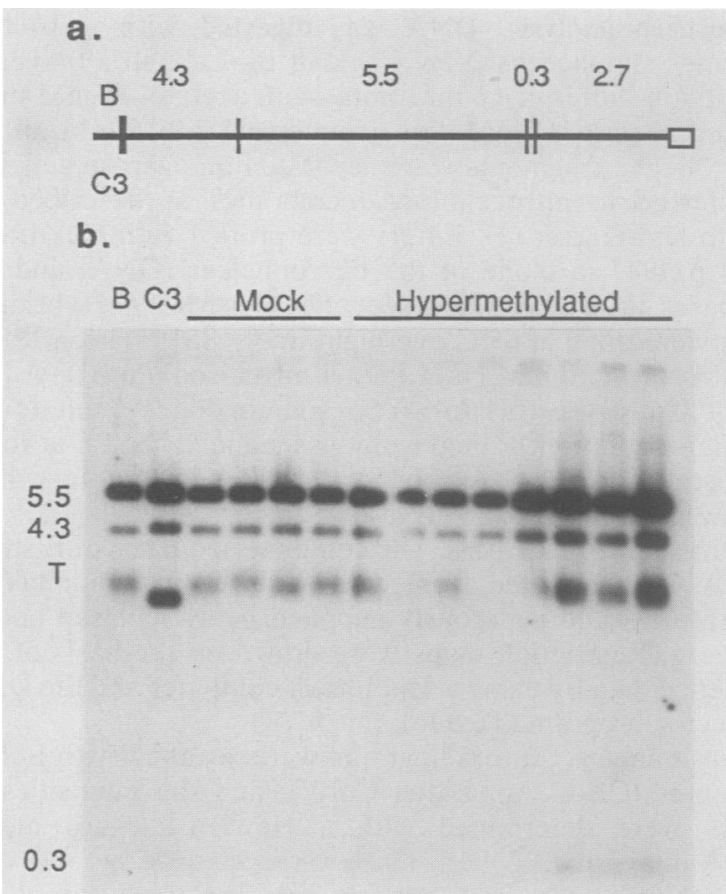

FIG. 2. Methylation state of ClaI sites in transformed cell lines. (a) Restriction map of sites for the restriction enzyme ClaI in B and C3 strain rDNAs. Half of the palindromic molecule is shown; the bar near the left indicates the center of symmetery, and the box at the right indicates the telomere. (b) Genomic DNA from the B strain host, the C3 strain, four cell lines transformed with mock-methylated rDNA from the $\mathrm{C} 3$ strain, and eight cell lines transformed with rDNA from the C3 strain methylated with ClaI methylase. All DNAs were digested with ClaI. The fragments were separated by electrophoresis through a $\mathbf{0 . 7 \%}$ agarose gel in TBE buffer for $\mathbf{3 0 0}$ V-h. The DNA was blotted to nitrocellulose and hybridized with nick-translated pTt947. The sizes of the fragments are indicated in kilobases to the left. T, Terminal fragment.

dam-, and EcoRI-methylated rDNAs and 4 injected with DNA mock methylated for each enzyme. Although trace amounts of B strain rDNA were present, densitometric scanning of the films suggested that at least $95 \%$ of the rDNA in the transformed cell lines was of the injected type (data not shown).

Hypermethylation lost during vegetative cell growth. rDNAs from transformed cell lines were examined to determine whether the hypermethylation was maintained throughout the 20 to 25 cell fissions required to establish clonal cell lines. Whole-cell DNA from transformed cell lines was digested with the restriction enzyme ClaI. Figure 2 shows an autoradiogram of a Southern blot of the DNA from 14 clonal cell lines digested with ClaI and hybridized with pTt947. The DNA from the B strain host had four bands at 5.5, 4.3, 2.7, and $0.3 \mathrm{~kb}$, as expected from the computer analysis of the sequence of B strain rDNA, indicating that the ClaI sites are not methylated in vivo.

Similar ClaI fragments were seen in DNA from the C3 strain from which the rDNA for injection was isolated. The terminal fragment from the rDNA of strain SL061a was about 200 base pairs shorter than the corresponding fragment from SB255. This was consistently observed in DNA digested with a variety of enzymes and is thought to be due to a difference in the number of telomeric $C_{4} A_{2}$ repeats $(17$, 28). 


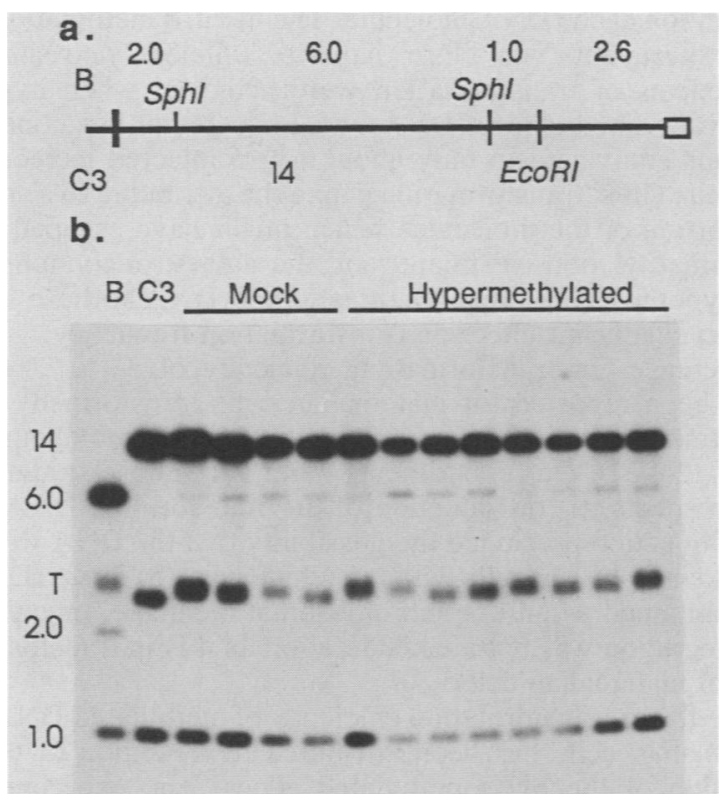

FIG. 3. Methylation state of EcoRI sites in transformed cell lines. (a) Map of sites for the restriction enzymes $S p h I$ and $E c o R I$ in $B$ and C3 strain rDNAs. (b) Genomic DNA from the B strain host, from the C3 strain, from four cell lines transformed with mockmethylated rDNA from the $\mathrm{C} 3$ strain, and eight cell lines transformed with rDNA from the C3 strain methylated with EcoRI methylase. All DNAs were digested with SphI and EcoRI. The fragments were separated by electrophoresis through a $0.7 \%$ agarose gel in TBE buffer for $300 \mathrm{~V}$-h. The DNA was blotted to nitrocellulose and hybridized with nick-translated pTt947. The sizes of the fragments are indicated in kilobases to the left. T, Terminal fragment.

There was no detectable methylation at $\mathrm{ClaI}$ sites in rDNA from strains transformed with hypermethylated rDNA (Fig. 2), even though these sites were methylated in the injected DNA (Fig. 1a). Thus, hypermethylation at the ClaI sites was not maintained through the 20 to 25 cell fissions required to establish the clonal cell line.

To assess the methylation of rDNA at the EcoRI sites in transformed cell lines, whole-cell DNA was digested with both SphI and EcoRI. The map of the restriction sites for these enzymes on B and C3 strain rDNAs is shown in Fig. 3a. SphI cuts B strain rDNA twice on each half of the palindromic molecule, generating a $2.0-\mathrm{kb}$ central fragment, a 6.0-kb internal fragment, and a $3.6-\mathrm{kb}$ distal fragment. The distal fragment is cut by $E c o \mathrm{RI}$, producing fragments of 1.0 and $2.6 \mathrm{~kb}$ (Fig. 3b). C3 strain rDNA lacks the inner SphI sites, and thus the 2.0- and 6.0-kb fragments are replaced with a 14-kb central fragment (Fig. 3b). This is thought to be restriction site polymorphism and not methylation polymorphism because plasmid DNA containing C3 rDNA was not cut at this site (data not shown). The predominance of the larger 14-kb fragment in the DNA from the transformed cell lines (Fig. 3b) supported the conclusion drawn from blots of DNA digested with BamHI that the injected rDNA represents most of the rDNA molecules in these cells.

Hypermethylation at the EcoRI site was eliminated during growth of the transformed cell lines. In DNA from cell lines transformed with hypermethylated rDNA, the 3.6-kb SphI fragment was cut by EcoRI in every case, giving 1.0- and 2.6-kb fragments analogous to those of the native rDNA and the mock-methylated controls (Fig. 3b).

The methylation state of rDNA from cells transformed with rDNA hypermethylated at the 58 GATC sites was assessed by digestion of the DNA with $\mathrm{MboI}$, which does not cut if the adenine on either strand is methylated. Figure 4b shows DNA from B strain cells cut with $M b o I$ and hybridized with pTt947. There are fragments at 3.8 and 1.4 $\mathbf{k b}$ and a host of small fragments of $0.8 \mathrm{~kb}$ or less which are not resolved on agarose gels. This is in agreement with the restriction map produced by computer analysis of the sequence of B strain rDNA (Figure $4 \mathrm{a}$ ), which predicts 28 small fragments. In accord with earlier studies $(4,22,23)$, a restriction site polymorphism was observed between $B$ and C3 strain rDNAs (Fig. 4b). Although the C3 strain rDNA was heavily hypermethylated at the time of injection (Fig. 1b), the rDNA in the transformed cell lines (Fig. 4b) was as readily digested with $\mathrm{MboI}$ as was the rDNA from $\mathrm{C} 3$ strain

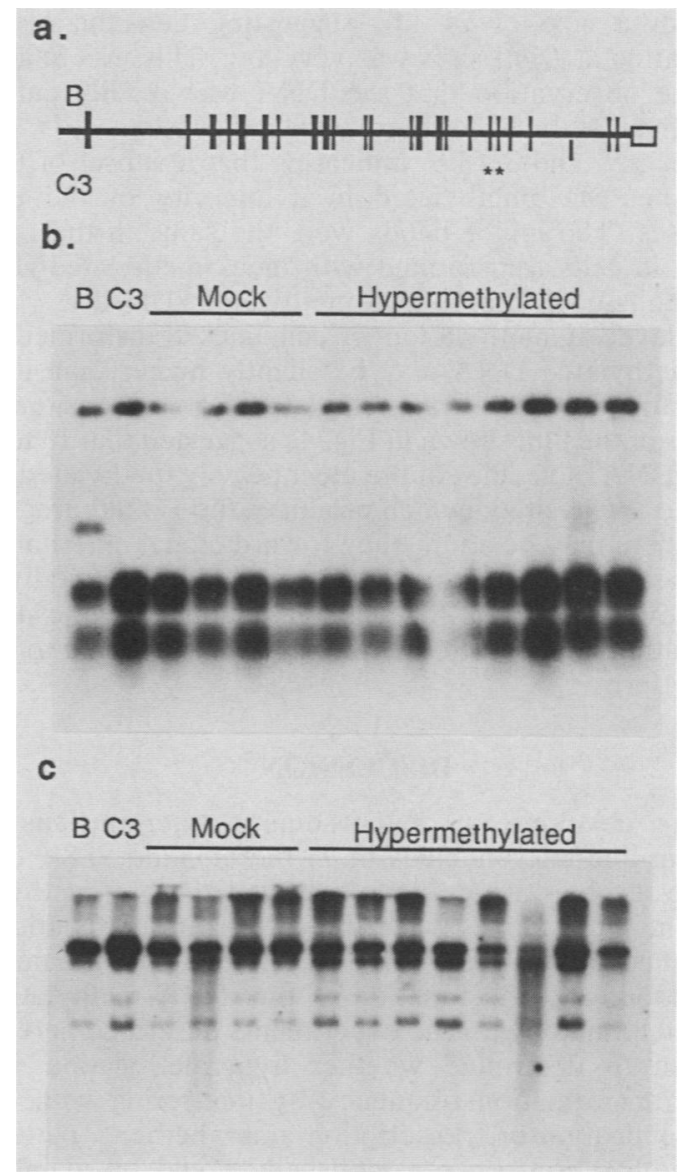

FIG. 4. Methylation state of dam sites in transformed cell lines. (a) Map of 5' GATC 3' sites in B and C3 strain rDNAs, derived from the sequence of $B$ strain rDNA. The exact position of the extra site in C3 strain rDNA is not known. It is placed within the restriction fragment on the basis of restriction of genomic DNA with Mbol (panel b). Two dam sites which are also ClaI sites are indicated by asterisks. (b) Genomic DNA from the B strain host, the C3 strain, four cell lines transformed with mock-methylated rDNA from the $\mathrm{C} 3$ strain, and eight cell lines transformed with rDNA from the $\mathrm{C} 3$ strain methylated with the dam methylase. All DNAs were digested with $M b o I$. The fragments were separated by electrophoresis through a $0.7 \%$ agarose gel in TBE buffer for $300 \mathrm{~V}-\mathrm{h}$. The DNA was blotted to nitrocellulose and hybridized with nick-translated pTt947. (c) The same DNAs as in panel b, digested with DpnI. The fragments were separated by electrophoresis in a $0.5 \%$ agarose gel for $300 \mathrm{~V}$-h. The sizes of the fragments are indicated in kilobases to the left. $T$, Terminal fragment. 
cells or that from cells transformed with mock-methylated rDNA. Thus, most of the methylation at dam sites was removed during clonal cell growth.

The large number of fragments generated with $\mathrm{MboI}$ makes analysis of the level of methylation at any particular site difficult. Computer analysis of the rDNA sequence revealed that the two dam sites marked with an asterisk in Fig. 4a were also ClaI sites. Since those sites were susceptible to ClaI in cells transformed with hypermethylated rDNA (Fig. 2), hypermethylation at those sequences was not maintained by the Tetrahymena methylase.

Digestion with DpnI, which cuts the DNA only at GATC sites which are methylated on both strands, provides a more sensitive test for low levels of methylation at dam sites. Figure 4c shows an autoradiogram of a blot containing cellular DNA from control and transformed strains digested with DpnI. Most of the DNA migrated at a position consistent with a size of $21 \mathrm{~kb}$, suggesting that the level of methylation at DpnI sites was very low. This was in accord with the observation that the DNA was readily cut with $M b o I$. In all of the lanes, there were minor bands at 17.2, 9.2, $7.2,5.3,3.9$, and $3.2 \mathrm{~kb}$, indicating that a subset of the 58 DpnI sites was methylated in a minority of the rDNA molecules. The minor bands were the same in the control strains, in cells transformed with mock-methylated rDNA, and in cells transformed with methylated rDNA.

The level of methylation in cell lines transformed with hypermethylated DNA may be slightly higher than it is in cells transformed with unmethylated DNA. Densitometric analysis of the film shown in Fig. 4c suggested that 15 to $25 \%$ of the rDNA molecules in the most heavily methylated lanes were cut at the site(s) which produces the 17.2-kb fragment. Thus, there may be a tendency toward clonal inheritance of hypermethylation at some of the sites which are methylated at low levels in the control cells, but qualitatively the state of methylation of rDNA in the transformants reverted to the in vivo pattern.

\section{DISCUSSION}

During development of the somatic macronucleus from the germ line micronucleus of $T$. thermophila, $0.8 \%$ of the adenine residues are de novo methylated to $N^{6}$-methyladenine. The mechanisms whereby patterns of methylation are established and maintained in the macronucleus are not well understood, and the function of this DNA methylation is completely unknown. The experiments described here were designed to determine whether hypermethylation would effect transformation frequency by interfering with either DNA replication or transcription and whether a pattern of hypermethylation, once established, would be maintained through several rounds of DNA replication.

Three samples of isolated rDNA were in vitro methylated with the bacterial ClaI, dam, and EcoRI methylases. The sequence 5' GATC 3', which is recognized by dam methylase, is methylated uniformly at several specific sites in the macronuclear genome of $T$. thermophila (13) and at a low level at five sites in the rDNA (4). One uniformly methylated EcoRI site has been found in the macronuclear DNA of $T$. thermophila (18). Although methylated ClaI sites have not yet been found in $T$. thermophila, one has been identified in the macronuclear DNA of the hypotrichous ciliate Oxytricha fallax (7).

In the experiments reported here, the transformation efficiency of Tetrahymena rDNA was not affected by methylation at the 58 dam sites, 6 ClaI sites, or 2 EcoRI sites present on each rDNA molecule. The in vitro methylation in our experiments was more than $99 \%$ efficient, and similar efficiencies of transformation were achieved when hypermethylated and control DNAs were injected at low concentrations equivalent to only about 4 or 5 injected molecules per cell. Thus, transformation cannot be attributed to a small proportion of the molecules which might have escaped the hypermethylation treatment, and the data strongly support the hypothesis that hypermethylation of rDNA at these sites has no significant effect on transformation frequency.

Decreases in transformation efficiency of 3- to 20-fold have been reported for mammalian cells transformed with hypermethylated versus mock-methylated heterologous $t k$ genes $(24,31)$. Our experiments differ from those studies in two respects. (i) Introduction of the transforming DNA by microinjection precluded the possibility that the DNA would be taken up by the cells with less efficiency. (ii) Since rDNA is maintained as an extrachromosomal molecule, efficiency of integration was not a consideration as it is in transformation of mammalian cells.

The lower transformation efficiency of methylated DNA in mammalian cells has been attributed to inhibition of transcription of the hypermethylated genes. The experiments reported here do not address the question of whether or not methylation of adenine has any effect on transcriptional activity because hypermethylation was not maintained through the 20 to 25 cell fissions of the clonal cell lines.

Analysis of DNAs from cell lines transformed with mockmethylated versus hypermethylated rDNA reveals similar levels of injected and host DNAs in the two types of transformants, indicating that methylation of these sites does not impair DNA replication. It should be noted, however, that none of the sites that were hypermethylated in this study are located in the region which is thought to contain the origin of replication of the extrachromosomal rDNA molecule $(8,16)$.

Replacement of endogenous B strain rDNA with injected C3 strain rDNA under conditions of selection in paromomycin was quite efficient. We estimated from the intensity of bands in gels of the rDNA stained with ethidium bromide that the injected DNA was at a concentration of 10 to 15 $\mathrm{ng} / \mu \mathrm{l}$. This means that we injected approximately 50 molecules into a host macronucleus with about 9,000 endogenous rDNA molecules. However, after 20 to 25 cell fissions, more than $95 \%$ of the rDNA was of the injected type. Lowering the concentration of the injected rDNA 10 -fold produced a slight decrease in the transformation efficiency of most samples tested at 3 days and a general trend of a greater increase in the proportion of transformed clones with drug introduced at 6 days rather than 3 days. This suggested that cells injected with fewer rDNA molecules took slightly longer to achieve a state of drug resistance and that very few injected molecules, perhaps only one or two, are required for eventual transformation.

De novo methylation of ClaI, dam, and EcoRI sites was not observed in any of the cell lines transformed with mock-methylated Tetrahymena rDNA. This suggests that naked DNA introduced into vegetatively growing cells is not methylated at sites which are not methylated in vivo. If such de novo methylation does occur, it is lost within the 20 to 25 cell fissions required to establish the clonal cell line.

As a general rule, hypermethylation of heterologous DNA in mammalian cell lines is not retained with $100 \%$ efficiency. Examination of the methylation state of transfected DNA in mouse $L$ cells over several generations has led to different interpretations as to the cause of incomplete methylation. In 
one case, the methylation was found to be unstable, and the reduced methylation was attributed to imperfect maintenance of the methylation pattern at each cell division (31). In another study, it was concluded that 30 to $40 \%$ of the methylation at a specific site was lost at transfection, but the remaining $70 \%$ was stable over 75 cell generations (27).

The experiments reported here had the advantage of examining the fate of hypermethylated sites in a homologous cell type. We found that methylation of the EcoRI and ClaI sites was lost during DNA replication. Furthermore, methylation of the 29 dam sites reverted to the same qualitative pattern as that observed in native rDNA. Therefore, methylation of a particular site does not provide sufficient impetus for maintenance of the methylation pattern, even when that site is methylated at a low level in vivo, and other factors must play the determining role in establishing the methylation pattern in extrachromosomal rDNA.

It is possible that rDNA represents a special case. Most of the molecule is very heavily transcribed, and the chromatin structure is highly ordered in the nontranscribed regions $(6$, 21). It will be of interest to determine whether methylation of other sites in the DNA of $T$. thermophila depends primarily on the sequence or on the position of the sites in the genome.

\section{ACKNOWLEDGMENTS}

We are grateful to $H$. Nielsen and J. Engberg for the sequence of the rDNA and to R. Sweeney for putting it onto the MacIntosh computer. We thank J. Wells and E. Capowski for helpful comments on the manuscript.

The work was supported by Public Health Service grants GM26210 and HD00547 to M.-C.Y. and GM32989 and BRSG S07 RR07044 to K.M.K. from the National Institutes of Health.

\section{LITERATURE CITED}

1. Allitto, B. A., and K. M. Karrer. 1986. A family of DNA sequences is reproducibly rearranged in the somatic nucleus of Tetrahymena. Nucleic Acids Res. 14:8007-8025.

2. Austerberry, C. F., and M.-C. Yao. 1987. Nucleotide sequence structure and consistency of a developmentally regulated DNA deletion in Tetrahymena thermophila. Mol. Cell. Biol. 7:435443.

3. Bird, A. P. 1978. Use of restriction enzymes to study eukaryotic DNA methylation: II. The symmetry of methylated sites supports semi-conservative copying of the methylation pattern. J. Mol. Biol. 118:49-60.

4. Blackburn, E. H., W.-C. Pan, and C. C. Johnson. 1983. Methylation of ribosomal RNA genes in the macronucleus of $T e$ trahymena thermophila. Nucleic Acids Res. 11:5131-5145.

5. Bromberg, S., K. Pratt, and S. Hattman. 1982. Sequence specificity of the DNA adenine methylase in the protozoan Tetrahymena thermophila. J. Bacteriol. 150:993-996.

6. Budarf, M. L., and E. H. Blackburn. 1986. Chromatin structure of the telomeric region and 3'-nontranscribed spacer of Tetrahymena ribosomal RNA genes. J. Biol. Chem. 261:363-369.

7. Cartinhour, S. W., and G. A. Herrick. 1984. Three different macronuclear DNAs in Oxytricha fallax share a common sequence block. Mol. Cell Biol. 4:931-938.

8. Cech, T. R., and S. L. Brehm. 1981. Replication of the extrachromosomal ribosomal RNA genes of Tetrhymena thermophila. Nucleic Acids Res. 9:3531-3543.

9. Din, N., and J. Engberg. 1979. Extrachromosomal ribosomal RNA genes in Tetrahymena: structure and evolution. J. Mol. Biol. 134:555-574.

10. Gorovsky, M. A., S. Hattman, and G. L. Pleger. 1973. $\left[N^{6}\right]$ methyladenine in the nuclear DNA of a eucaryote, Tetrahymena pyriformis. J. Cell Biol. 56:697-701.

11. Gorovsky, M. A., M.-C. Yao, J. B. Keevert, and G. L. Pleger. 1975. Isolation of micro- and macronuclei of Tetrahymena pyriformis. Methods Cell Biol. 9:311-327.

12. Gruenbaum, Y., H. Cedar, and A. Razin. 1982. Substrate and sequence specificity of a eukaryotic DNA methylase. Nature (London) 295:620-622.

13. Harrison, G. S., R. C. Findly, and K. M. Karrer. 1986. Sitespecific methylation of adenine in the nuclear genome of a eucaryote, Tetrahymena thermophila. Mol. Cell. Biol. 6:2364 2370.

14. Holliday, R., and J. E. Pugh. 1975. DNA modification mechanisms and gene activity during development. Science 187:226232.

15. Keshet, I., J. Lieman-Hurwitz, and H. Cedar. 1986. DNA methylation affects the formation of active chromatin. Cell 44:535-543.

16. Larson, D. D., E. H. Blackburn, P. C. Yaeger, and E. Orias. 1986. Control of DNA replication in Tetrahymena involves a cis-acting upstream repeat of a promoter element. Cell 47:229 240 .

17. Larson, D. D., E. A. Spangler, and E. H. Blackburn. 1987. Dynamics of telomere length variation in Tetrahymena thermophila. Cell 50:477-483.

18. Martindale, D. M., H. M. Martindale, and P. J. Bruns. 1986. Tetrahymena conjugation-induced genes: structure and organization in macro- and micronuclei. Nucleic Acids Res. 14:13411354.

19. Orias, E., and P. J. Bruns. 1976. Induction and isolation of mutants in Tetrahymena. Methods Cell Biol. 13:247-282.

20. Orias, E., M. Flacks, and B. H. Satir. 1983. Isolation and ultrastructural characterization of secretory mutants of Tetrahymena thermophila. J. Cell Sci. 64:49-67.

21. Palen, T. E., and T. R. Cech. 1984. Chromatin structure at the replication origins and transcription-initiation regions of the ribosomal RNA genes of Tetrahymena. Cell 36:933-942.

22. Pan, W.-C., and E. H. Blackburn. 1981. Single extrachromosomal ribosomal RNA gene copies are synthesized during amplification of the rDNA in Tetrahymena. Cell 23:459-466.

23. Pan, W.-C., E. Orias, M. Flacks, and E. H. Blackburn. 1982. Allele-specific, selective amplification of a ribosomal RNA gene in Tetrahymena thermophila. Cell 28:595-604.

24. Pollack, Y., R. Stein, A. Razin, and H. Cedar. 1980. Methylation of foreign DNA sequences in eukaryotic cells. Proc. Natl. Acad. Sci. USA 77:6463-6467.

25. Riggs, A. D. 1975. X-inactivation, differentiation, and DNA methylation. Cytogenet. Cell Genet. 14:9-25.

26. Sneider, T. W., W. M. Teague, and L. M. Rogachevsky. 1975. $S$-Adenosylmethionine: DNA-cytosine 5-methyltransferase from a Novikoff rat hepatoma cell line. Nucleic Acids Res. 2:16851700.

27. Stein, R., Y. Greenbaum, Y. Pollack, A. Razin, and H. Cedar. 1982. Clonal inheritance of the pattern of DNA methylation in mouse cells. Proc. Natl. Acad. Sci. USA 79:61-65.

28. Tondravi, M. M., and M.-C. Yao. 1986. Transformation of Tetrahymena thermophila by microinjection of ribosomal RNA genes. Proc. Natl. Acad. Sci. USA 83:4369-4373.

29. Turnbull, J. F., and R. L. P. Adams. 1976. DNA methylase: purification from ascites cells and the effect of various DNA substrates on its activity. Nucleic Acids Res. 3:677-695.

30. Wang, R. Y.-H., L.-H. Huang, and M. Ehrlich. 1984. Human placental DNA methyltransferase: DNA substrate and DNA binding specificity. Nucleic Acids Res. 12:3473-3489.

31. Wigler, M., D. Levy, and M. Perucho. 1981. The somatic replication of DNA methylation. Cell 24:33-40.

32. Ysraeli, J., R. S. Adelstein, D. Melloul, U. Nudel, D. Yaffe, and H. Cedar. 1986. Muscle specific activation of a methylated chimeric actin gene. Cell 46:409-416. 